\title{
Zingiber officinale ROSCOE: ASPECTOS BOTÂNICOS E ECOLÓGICOS '
}

\author{
Zingiber officinale ROSCOE: BOTANICAL AND ECOLOGICAL ASPECTS
}

ELPO, Eliane Rose Serpe ${ }^{2}$; NEGRELLE, Raquel Rejane Bonato ${ }^{3}$

\begin{abstract}
' Parte da tese de Doutorado em Agronomia - Produção Vegetal - UFPR
${ }^{2}$ Doutora em Produção Vegetal - UFPR; Professora do Departamento de Saúde Comunitária - UFPR e-mail: erselpo@ufpr.br

${ }^{3}$ Doutora em Ecologia; Professora do Departamento de Botânica, Laboratório OIKOS - UFPR

Recebido em: 01/2004

Aprovado em: 04/2004

1 INTRODUÇÃO
\end{abstract}

O gengibre (Zingiber officinale Roscoe - Zingiberaceae) é uma planta herbácea perene, cujo rizoma é amplamente comercializado em função de seu emprego alimentar e industrial, especialmente como matéria-prima para fabricação de bebidas, perfumes e produtos de confeitaria como pães, bolos, biscoitos e geléias, e popular medicinal (excitante, estomacal e carminativo) (DAHLGREN et al., 1985; JOLY, 1985; CORRÊA JUNIOR et al., 1994; TROPICAL, 2000; INFORMAÇÕES, 2002). Várias propriedades do gengibre foram comprovadas em experimentos científicos, citando-se as atividades anti-inflamatória, antiemética e antináusea, antimutagênica, antiúlcera, hipoglicêmica, antibacteriana entre outras (KADA, 1978; NAMAKURA e YAMAMOTO, 1982; NAGABHUSHAN et al., 1987; CHEEMA et al., 1988; BONE et al., 1990; YOSHIKAWA et al., 1992; YOSHIKAWA et al., 1994; ONTENGCO et al., 1995; LONIEWSKI et al., 1998; WHO, 1999; UTPALENDU et al., 1999).

A cultura do gengibre tornou-se efetivamente comercial no Estado do Paraná somente nas últimas décadas, após introdução de variedade de rizomas gigantes por agricultores japoneses (TAVEIRA MAGALHÃES et al., 1997). Atualmente, o Paraná desponta como o maior produtor nacional de gengibre (rizomas "in natura") totalizando 3.945,00 toneladas/ano. Esta cultura ocupa uma área aproximada de 201 ha, englobando 26 municípios produtores. Incluído, no grupo "Especiarias", o valor bruto de produção agrícola (VBP) safra 01/02 totalizou R\$ 3.353.250, 19 (PARANÁ, 2003).

O principal produtor estadual de gengibre "in natura" é o município de Morretes - PR, com uma produtividade média, safra 01/02, de 18,0 t/ha, correspondendo a $60 \%$ da produção estadual (PARANÁ, 2003).

Assim, dada a importância econômica regional do cultivo do gengibre, buscou-se com este trabalho apresentar uma revisão de literatura englobando aspectos botânicos e ecológicos, visando subsidiar a melhoria da qualidade da cadeia produtiva deste produto no Estado do Paraná.

\section{DESENVOLVIMENTO DO TEMA}

\subsection{Classificação Botânica}

Zingiber officinale foi primeiramente descrito, em 1807, pelo botânico inglês William Roscoe (1753-1813). Está inserido na família Zingiberaceae, grupo tropical especialmente abundante na região Indo-Malasia que engloba mais de 1200 espécies de plantas incluídas em 53 gêneros. $\bigcirc$ gênero Zingiber inclui aproximadamente 85 espécies. $\bigcirc$ nome deste 
gênero, Zingiber, deriva de uma palavra em sânscrito que significa em forma de "chifre" em referência às protuberâncias na superfície do rizoma (STEVEN, 2002).

Botanicamente, o gengibre está assim categorizado (CLASSIFICATION, 2003):

Reino Pantae

Filo Magnoliophyta

Classe Liliopsida

Ordem Zingiberales

Família Zingiberaceae Lindl., 1835, nom.cons.

Gênero Zingiber P. Moller, 1754

Epíteto: Zingiber officinale Roscoe, 1807.

- Sinonímia (ZINGIBER, 2003a):

Amomum zingiber $\mathrm{L}$

Curcuma longifolia Wall

Zingiber aromaticum Noronha

Z. majus Rumphius

Z. missionis Wall

Z. sichuanense Z. Y. ZHUN et al.

Z. zingiber (L.) H. Karst.

- Nomes Populares (TREASE, 1966; BRITISH HERBAL PHARMACOPOEIA, 1983; JOLY, 1985; JACKSON; SNOWDON, 1990; PHARMACOPOEA HELVETICA, 1993; BRITISH HERBAL PHARMACOPOEIA, 1993; WHO, 1999; HERBAL MEDICINE, 2000; KATZER, 2002):

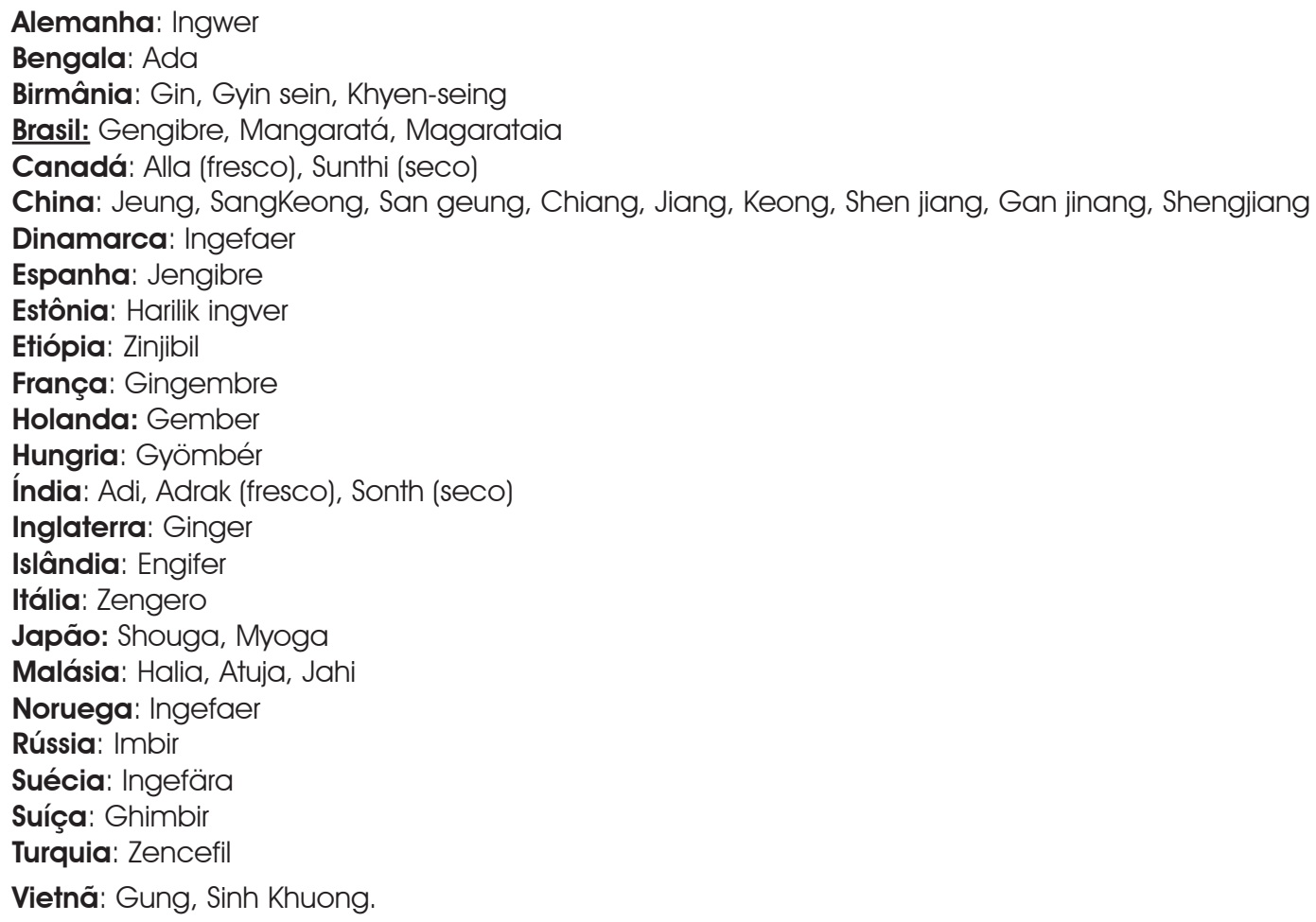

\subsection{Origem e Distribuição}

O gengibre é uma erva rizomática originária do sudoeste da Ásia e do Arquipélago Malaio, onde a sua cultura tem grande importância, não somente para o consumo local da população indígena, como também para a exportação, destinada a países ocidentais que o consomem em grandes quantidades (GOVINDARAJAN, 1982; CHEN et al., 1986; CORRÊA JUNIOR et al., 1994; WHO, 1999). 


\subsection{Descrição Geral}

O gengibre é uma planta herbácea, perene, de rizoma articulado, septante, carnoso, revestido de epiderme rugosa e de cor pardacenta (Figura 1). Na parte superior, possui pequenos tubérculos anelados, resultantes da base de antigos caules aéreos. Na parte inferior, possui muitas raízes adventícias, cilíndricas, carnosas e de cor brancacentas. Os caules são eretos, formados por muitas folhas dísticas, sendo as basilares simples com bainhas glabras e estriadas no sentido longitudinal. As bainhas superiores são amplexicaules na base e terminam com um limbo, linear e lanceolado. As inflorescências com espigas ovóides ou elipsóides formam-se no ápice dos pedúnculos que saem do rizoma, revestidos por escamas invaginantes e imbricadas, obtusas, decrescentes da base para o ápice. As flores apresentamse zigomorfas, hermafroditas, com coloração amarelo-esverdeada. As brácteas florais orbiculares possuem cálice e corola denteados que envolvem uma só flor. O fruto é uma cápsula que se abre em três lóculos e abriga sementes azuladas com albúmen carnoso (DAHLGREN et al., 1985; PURSEGLOVE, 1992; CORRÊA JUNIOR et al., 1994; FRANCO, 1996; WHO, 1999).

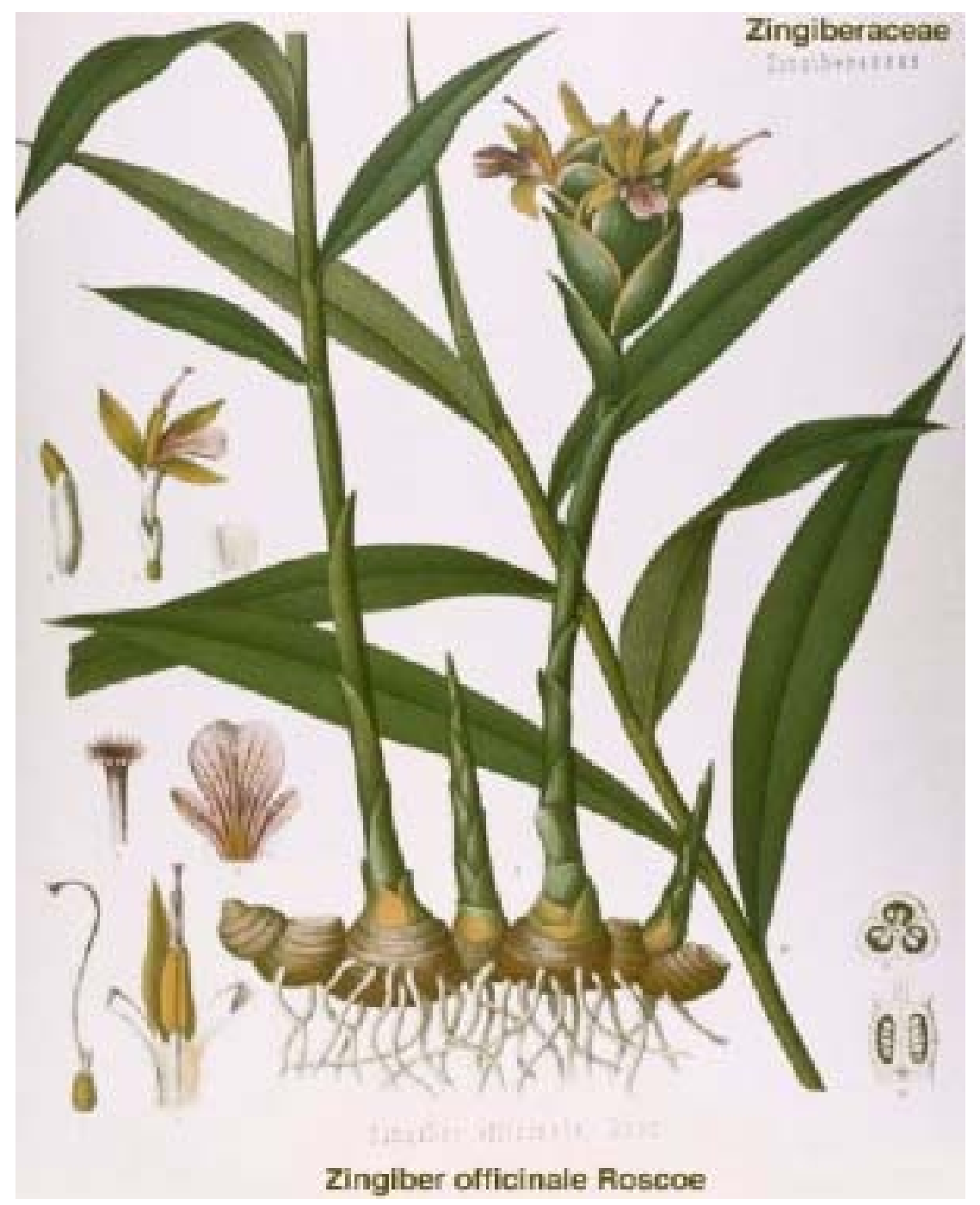

FIGURA 1 - Zingiber officinale Roscoe: vista geral da planta e detalhes das flores. Fonte: Zingiber (2003b). 


\subsection{Rizoma}

\subsubsection{Elementos morfológicos característicos}

O rizoma do gengibre apresenta corpo alongado, um pouco achatado, com ramos fragmentados irregularmente, de 3 a $16 \mathrm{~cm}$ de comprimento, 3 a $4 \mathrm{~cm}$ de largura e $2 \mathrm{~cm}$ de espessura. Externamente, sua coloração vai do amarelo couro à marrom brilhante, estriado na longitudinal, algumas vezes fibroso, com terminações conhecidas como "dedos" que surgem obliquamente dos rizomas; achatadas, obovatadas, curtas, de 1 a $3 \mathrm{~cm}$ de comprimento. O amido é o principal constituinte do córtex e cilindro central. Internamente, de cor marrom amarelado, apresentando uma endoderme amarela, que separa o córtex estreito do estelo largo, com numerosos feixes fibrovasculares e abundantes células oleoresinosas com conteúdos amarelos e numerosos pontos acinzentados, feixes vasculares espalhados sobre toda a superfície (TREASE, 1966; BRITISH HERBAL PHARMACOPOEIA, 1983; BRITISH PHARMACOPOEIA, 1993; WHO, 1999).

\subsubsection{Elementos histológicos característicos}

Microscopicamente, apresenta córtex isodiamétrico, células parenquimatosas de parede fina contendo grânulos de amido; o hilo medindo até $50 \mathrm{~mm}$ de comprimento, 25 $\mathrm{mm}$ de largura e $7 \mathrm{~mm}$ de espessura. Células de secreção de paredes suberizadas contendo oleoresinas de cor marrom amareladas e feixes acompanhados por fibras vasculares espalhados no córtex e cilindro central. A endoderme, de cor marrom claro, com células de parede finas e radiais suberizadas. O estelo, com tecido parenquimatoso, numerosas células secretoras, oleoresinas amarelas espalhadas, feixes vasculares não lignificados, reticulados, escalariforme e vasos espirais, freqüentemente acompanhados por células estreitas. Pigmento marrom escuro suportado por fibras de parede fina com lúmen largo, pequenas fendas oblíquas e lamela média lignificada. Muitas fibras são septadas (YOUNKGEN, 1950; TREASE, 1966; PHARMACOPOEA HELVETICA, 1993; BRITISH PHARMACOPOEIA, 1993; WHO, 1999).

\subsection{Exigências Ambientais}

O cultivo gengibre requer solos bem drenados, arenosos, férteis e ricos em matéria orgânica. Exige ainda, clima tipicamente tropical, quente e úmido, com períodos bem definidos de calor e umidade para um rápido e excelente desenvolvimento da cultura (DONALÍSIO et al., 1980; EPAGRI, 1998; TAVEIRA MAGALHÃES et al., 1997; LISSA, 1996).

As maiores produtividades obtidas nas regiões produtoras dos Estados de São Paulo e Paraná foram constatadas em solos areno-argilosos, friáveis, bem drenados. Regiões estas, que devido às suas peculiaridades climáticas de litoral não exigem irrigações nos períodos críticos de crescimento (DONALISIO et al., 1980; TAVEIRA MAGALHÃES et al., 1997). Adicionalmente, DONALISIO et al. (1980) salientam que o gengibre, também pode ser cultivado em regiões onde haja temperaturas elevadas e chuvas abundantes durante 06 a 08 meses, podendo até ser cultivado ao nível do mar, e em altitudes superiores a 1500 m. Neste contexto, LISSA (1996) comenta que a altitude aparentemente pouco influi na produção, pois tanto em regiões altas, como na Índia a 1500 m acima do mar, e em regiões baixas, 
como no litoral do Brasil, quase ao nível do mar, sem grandes diferenças em seu desenvolvimento. PURSEGLOVE (1992) cita que a principal área de produção de gengibre na Jamaica é uma região montanhosa, a 450 à $900 \mathrm{~m}$ de altitude com temperatura média anual de $21^{\circ} \mathrm{C}$ e chuvas médias de $1800 \mathrm{~mm}$ por ano. Nesta região, os solos são arenoargilosos, com calcáreo, sendo que os declives excessivamente íngremes facilitam a drenagem.

\section{CONCLUSÃO}

A cultura de gengibre tem grande importância, não somente para o consumo local da população, em função de seu emprego alimentar e industrial, especialmente, como matéria-prima para fabricação de bebidas, perfumes e produtos de confeitaria, e popular medicinal, como também para a exportação, destinada a países ocidentais, que o consomem em grandes quantidades. Quanto às exigências ambientais, o cultivo gengibre requer solos bem drenados, arenosos, férteis e ricos em matéria orgânica. Exige ainda, clima tipicamente tropical, quente e úmido, com períodos bem definidos de calor e umidade para um rápido e excelente desenvolvimento da cultura.

\section{REFERÊNCIAS}

BRITISH HERBAL PHARMACOPOEIA. London: British Herbal Medicine Association, p. 239-240, 1983.

BRITISH HERBAL PHARMACOPOEIA. London: British Herbal Medicine Association, p.87, 1996.

BRITISH PHARMACOPOEIA. London: her Magesty's Stationery Office, 1993; add. 1994, 1995, 1996, 1997.

CHEN, C. C.; KUO, M. C.; HO, C. T. High Performance Liquid Chromatographic determination of Pungent gingerol compounds of ginger. Journal of Food Science, v.51, n. 5, p. 1364-65, 1986.

CLASSIFICATION. Disponível em: < http://plants.usda.gov. > . Acesso em: 27/10/2003.

CORRÊA JUNIOR, C.; MING, L. C.; SCHEFFER, M. C. Cultivo de plantas medicinais, condimentares e aromáticas. 2.ed. Jaboticabal: FUNEP, 1994. 151p.

DAHLGREN, R. M. T.; CLIFFORD, H. T.; YEO, P. F. The Families of the Monocotyledons. New York: Springer, p. 360-364, 1985.

DONALÍSIO, M. G. R.; SOUZA, C. J.; DUARTE, F. R. Instruções para o cultivo do gengibre. O Agronômico, Campinas, V. 32, p. 176-180, 1980.

EMPRESA DE PESQUISA AGROPECUÁRIA E EXTENSÃO RURAL DE SANTA CATARINA S. A. - EPAGRI. Normas técnicas da cultura do gengibre. Litoral Catarinense e Litoral Paranaense. Florianópolis: EPAGRI/EMATER/PR/IAPAR, 1998. 26P. (EPAGRI. Sistemas de Produção, 30).

FRANCO, L. L. As sensacionais $\mathbf{5 0}$ plantas medicinais campeãs de poder curativo. v. 1, Curitiba: Santa Mônica, p. 143-145, 1996.

GOVINDARAJAN, V. S. Ginger-Chemistry, Technology and Quality Evaluation: Part I - CRC Critical Reviews in Food Science and Nutrition. Quensland, 17: 98, 1982.

HERBAL MEDICINE. Herb monographs, based on those created by a special expert committee of the German Federal Institute for Drugs and Medical devices. 1. ed. USA, p. 153-159, 2000.

JACKSON, B. P.; SNOWDON, D. W. Atlas of microscopy of medicinal plants, culinary herbs and spices. London, p. $110-111,1990$.

JOLY, A. B. Botânica. 7. ed. São Paulo: Editora Nacional, p. 722-723, 1985.

KATZER. Disponível em: < http://www-ang.kfunigraz. ac.at/ katzer /engl/ Zing _ off.html >. Acesso em: 26/03/ 2002.

LISSA, S. L. Cultura do Gengibre. Curitiba: EMATER/PR, 1996. 12 p.

PHARMACOPOEA HELVETICA. 7. ed. v. 1-4 ind. Supplements 1989, 1990, 1991, 1992 et 1993. Editeur: Département Federal de I'Intérieur 3003, Berne, 1993.

PURSEGLOVE, J. W. Tropical crops. Monocotyledons, USA: Longman Singapore Publishers Pte Ltd, p. 533-540, 1992. STEVEN. Disponível em: < http://www. stevenfoster. com/education/ monograph /ginger. html >. Acesso em: 16/ 10/2002.

TAVEIRA MAGALHÃES, M. et al. Gengibre (Zingiber officinale Roscoe) Brasileiro: Aspectos gerais, óleo essencial e oleoresina. Parte 2 - Secagem, óleo essencial e oleoresina. Ciência e Tecnologia de Alimentos, Campinas, v. 17 , 
n. 2, p. 132-136, 1997.

TREASE, G. E. A textbook of Pharmacognosy. 9.ed., London: Baillière, Tindall and Cassell, p. 340-348, 1966.

WHO. WORLD HEALTH ORGANIZATION. Quality control methods for medicinal plant materials. Geneva, 1998.

$115 \mathrm{p}$.

WHO. WORLD HEALTH ORGANIZATION. Monographs on selected medicinal plants. v. 1. Geneva, p. 277-287, 1999. YOUNKGEN, H. W. Textbook of Pharmacognosy, 1950, p. 224-227.

ZINGIBER. Disponível em: < http://mobot.mobot.org/cgi-bin/search_vast > . Acesso em: 27/10/2003a.

ZINGIBER. Disponível em: < http://www.healasthma.com/herbs.html > . Acesso em: 27/10/2003b. 